\title{
MANIFESTAÇÕES NEUROLOGICAS NAS ENDOCARDITES INFECCIOSAS - REVISAAO DE 103 CASOS ESTUDADOS - 84 CASOS DO HOSPITAL DOS SERVIDORES DO ESTADO-R.J. (1947-1978) E 19 CASOS DO HOSPITAL ESTADUAL SÃO SEBASTIAOO-R.J. (1975-1978)*
}

\author{
Adrelirio Jose Rios Gonçalves* Raymundo Dias Carneiro** Francisco Duarte*** \\ Ana Maria Miranda Pinto*** Marcia dos Santos Lazera**** Luiz Sergio Guedes Barbosa***** \\ Iranildo Cabral da Costa***** Niobe Furtado Barbosa****** Paulo Mendes Pecanha****** \\ Carlos Roberto de Vasconcelos Teixeira****** Helena Lagreca****** Paulo A. Lopes********
}

Cs autores fazem uma revisão de 103 casos de endocardites infecciosas, dos quais 52 apresentaram manifestações neurológicas. Dos 52 que não tiveram problemas neurológicos, 39 faleceram (75\%), enquanto que dos 51 que não tiveram alteraçbes do sistema nervoso, apenas 18 evoluíram para o obito (35,3\%).

A endocardite infecciosa com manifestacões neurológicas, na presente série, foi dominante no sexo masculino. Os grupos etários mais envolvidos foram as crianças, adolescentes e adultos jovens. Houve outro pico importante em pacientes acima de 50 anos. Os critérios para o diagnóstico de endocardite infecciosa utilizados no presente estudo, foram os clássicos, acrescidos de outros considerados de extrema utilidade, à medida que a experiéncia foi sendo acumulada, acompanhando paralelamente as modificações dos padröes etiológicos, assim como as alterações dos espectros clínicos da doença, conseqüentes a muitos fatores aqui discutidos.

Os principais distürbios neurologicos observados foram as manifestacôes meningeias, $25 / 52$ (48,1\%), a/teracões do comportamento, $20 / 52$ (38,4\%), fenômenos motores (paralisias e paresias), $20 / 52$ (38,4\%). Alterações do nível de consciéncia (torpor ou coma), ao lado de outras menos comuns, como cefaleia $16 / 52$ (26,9\%), convulsóes, $10 / 52$ (19,2\%), afasia 7/52 (13,5\%) e manchas de Roth, $7 / 53(13,5 \%)$.

As manifestações neurológicas frequentemente foram múltiplas em um mesmo paciente. Nas formas de endocardite, foram em muitos casos praticamente as alteracóes que abriram e dominaram a cena clínica. As mais comuns foram: sindrome meningeia, sindrome vascular e encefalopatia tóxica. Foi difícil, em conseqüéncia de múltiplas manifestaç̃es neurológicas num mesmo paciente, estabelecer critérios entre a lesão neurológica e o prognóstico, embora o coma profundo, as convulsões, os distúrbios motores acentuados, a meningite e as alteraçóes do comportamento, isoladamente ou em assaciação, façam com que o mesmo seja bem mais sério.

O germe mais encontrado em nossa série foi o Staphylococcus aureus, relacionado com formas agudas da infecção endocárdica, aliado a processos destrutivos valvulares e a serias alterações neurologicas tais como meningite, encefalite, infartos, hemorragias $e$ abcessos cerebrais.

Os principais achados neurológicos referentes à patologia, no estudo de 15 casos, são apresentados ao lado de conclusões tiradas de reflexões sobre o material analisado e da experiéncia vivida. Uma revisäo da literatura e feita desde os trabalhos iniciais sobre a doença até os dias de hoje, ficando evidenciada a importância do tema pelas grandes contribuicões apresentadas pelos diferentes autores.

\section{INTRODUÇÃO}

William Osler, discutindo as "Malignant Endocarditis" nas Gulstonian Lectures" ${ }^{39}$, assinalava já em 1885 o que ele tinha observado da história natural da doença e que chamou de "the cerebral group". Dizia o grande clínico que "a considerable number of cases of malignant endocarditis come under observation, perhaps, in hospital practice, for the first time, with symptoms of cerebral or even cerebrospinal trouble". Completando, o que é hoje conhecido através da literatura e da experiência acumulada, ia mais adiante Osler:"Very

* Médico do Hospital dos Servidores do Estado (Serviço de Clínica Médica) e do Hospital Estadual São Sebastiāo - R.J.

** Chefe do Servico de Cardiologia do H.S.E.

* * Chefe de Clínica do Servico de Anatomia Patológica do H.S.E.

* * * Medicas do Hospital Estadual São Sebastião

**** Medicos do H.S.E. (Servico de Clínica Medica)

***** Médicos Residentes do Servico de Clínica Médica do H.S.E.

******* Medica Residente do Servico de Anatomia Patológica do H.S.E.

******* Professor do Departamento de Medicina Preventiva da Faculdade de Medicina, U.F.R.J. Chefe de Clínica do Hospital Estadual São Sebastião. 
many of these cases die within two or three days of admission, and the question of diagnosis has usually to be suspended indeed, in looking over the records of eleven instances in which these cerebral symptoms were early, they appear to run a more rapid course than other cases".

As manifestações neurológicas podem abrir o quadro clínico das endocardites infecciosas (particularmente das formas fulminantes), e quando presentes ensombrecem o prognóstico dos enfermos. Quando tal comportamento clinico é visto, freqüentemente estes pacientes recebem outros rótulos diagnósticos tais como: meningoencefalite, síndrome vascular cerebral e encefalopatia tóxica. É também evidente que as manifestações neurológicas são importantes achados clínicos ou anátomo-patológicos quando a endocardite infecciosa não é reconhecida e deixada de lado seguindo sua

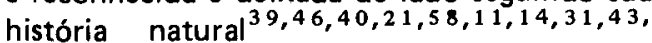
$60,61,41,26,28,52$. O envolvimento do sistema nervoso nestas infecções constitui um importante aspecto clínico, pois não somente pode ser um dos elementos chave que levam ao diagnóstico, como também ser o sistema nervoso a sede de complicações graves com sequelas importantes tais como: distúrbios motores, afasia, etc. . . Pode ainda o sistema nervoso ser o local de impacto de alterações severas, como aneurismas micóticos, vasculites, e que em muitos casos são os eventos finais da história natural da doença. Énfase deve ser dada a tão importantes manifestações clí. nicas pois, como vimos, poderão ser as alterações iniciais capazes de abrir o quadro clínico induzindo ao diagnóstico, ou ser eventualidades que ensombrecem o prognóstico quando surgem, inclusive causando morte em muitos casos ou deixando sequelas graves.

\section{MATERIAL, MÉTODO E ALGUNS COMENTARIOS - APRESENTAÇÃO DO MATERIAL E ANÁLISE DOS PRINCIPAIS DADOS OBTIDOS}

É uma revisão de 103 casos por nós estudados no H.S.E. (1947-1978), 84 casos, e no H.E.S.S. (1975-1978), 19 casos. $O$ diagnóstico de necropsia foi confirmado em 35 , sendo que destes, 15 são apresentados por terem exibido manifestações clínicas e anátomo-patológicas de envolvimento do sistema nervoso. Os critérios utilizados para o diagnóstico de endocardite infecciosa foram os seguintes:
1. Achados exclusivos de necropsia.

2. Lesão cardíaca orgânica $\times$ febre $\times$ hemocultura positiva.

3. Lesão cardíaca orgânica $x$ febre $x$ hemocultura positiva $x$ tromboembolismo.

4. Lesão cardíaca orgânica $\times$ febre $\times$ tromboembolismo sem hemocultura positiva (ou por serem negativas ou por não terem sido feitas).

5. Septicemia $x$ aparecimento de sopro orgânico $x$ anemia $x$ alterações ecocardiográficas.

6. Septicemia $x$ anemia $x$ manifestações neurológicas $x$ tromboembolismo periférico (vasculite) $x$ alterações ecocardiográficas (válidas principalmente nas formas agudas).

7. Septicemia $x$ anemia $x$ aparecimento de so. pro orgânico.

8. Septicemia $x$ anemia $x$ aparecimento de sopro orgânico $x$ comprovação cirúrgica para correção de distúrbios hemodinâmicos ou controle da infecção.

$\mathrm{Na}$ revisão do material e método foram incluídos os critérios clássicos do diagnóstico das endocardites infecciosas acrescidos de outros que julgamos serem importantes e perfeitamente corretos, e que fizeram parte de nossa experiência. Achamos que poderão, às vezes, serem incluídos casos duvidosos, utilizando os critérios por nós adotados. No entanto, a experiência com casos recentes, particularmente de formas agudas da condição, nos mostrou que tais critérios deverão ser utilizados e são muito úteis. Tal conduta deverá ser por nós seguida no futuro, em conseqüência da importância desta infecção, dos diagnósticos não feitos ou tardios, e da alta mortalidade e morbidade da doença entre nós. Assim, pensamos. que neste terreno é sempre preferível errar por excesso do que por carência, e que alguns casos passam sem diagnóstico mesmo utilizando critérios mais amplos para o reconhecimento.

A experiência que será mostrada, embora seja de épocas diferentes e até mesmo de hospitais distintos, podendo não refletir uma idéia exata estatística, será capaz de avaliar quão importantes são os fenômenos da esfera neuro-psiquiátrica em tão palpitante tema de medicina interna. É evidente que, dependendo da atenção do pesquisador e dos critérios adotados, estas alterações serão mais ou menos freqüentes nos diferentes trabalhos. Os critérios por nós utilizados para os pacientes serem incluídos como tendo manifestações neurológicas foram: 
a) Presença de alterações do comportamento tais como: agitação, sonolência, torpor, flutuação do nivel de consciência, delírio, alucinação, coma, alteração psicótica, afasia, disartria, alterações de fundo de olho, comprometimento de medula ou nervos periféricos.

b) Encontro de manifestações cérebro-vasculares ou o aparecimento das mesmas na evolução.

c) Convulsões em pacientes que não tinham história prévia.

d) Síndrome meningeia com alterações liqüóricas.

Cefaléia foi um dado pesquisado, porém de menor importância devido a pouca especificidade, embora 16 pacientes a tenham relatado. Em 15 pacientes que exibiram alterações clínicas neurológicas durante a doença e nos quais a autópsia foi realizada, os achados neuropatológicos são descritos e mostrados. Enfatizamos, no intuito não somente de alertar mas também de pôr em evidência alguns dados estatísticos, que os 19 pacientes admitidos no Hospital Estadual São Sebastião, incluídos no estudo ora apresentado, foram para lá enviados com o diagnóstico de meningoencefalite por apresentarem síndrome meningeia $\mathrm{e}$ alterações liquóricas, embora algumas tivessem outros achados neurológicos tais como encefalopatia tóxica e síndrome vascular cerebral. Todas, sem exceção, foram formas agudas de endocardite bacteriana e, quando hemoculturas positivas foram obtidas, o estafilococo áureo foi o germe responsável.

Importantes fatos a serem assinalados neste material por nós colhido no H.E.S.S. foram a idade dos pacientes (crianças, adolescentes e adultos jovens) que tiveram predominantemente porta de entrada cutânea (usualmente através de furúnculos, feridas infectadas, piodermites e aborto provocado); foi neste material também que, através da porta de entrada, manifestações neurológicas e estigmas periféricos (petéquias conjuntivas, hemorragias subungueais, vasculites cutâneas, nódulos de Osler, sinal de Roth e lesões de Janewayl observados em muitas ocasiões $e$, às vezes, em um mesmo paciente, que tivemos a percepção de que os critérios clássicos para o diagnóstico têm que ser ampliados. Exemplificando, em muitos deles a soprologia somente apareceu com 2 ou 3 semanas de evolução (sopros usualmente de insuficiência mitral ou regurgitação aórtica), ou em poucos, nem mesmo soprologia surgiu e os estudos ecocardiográficos demonstraram a presença de vegetações de válvulas, responsáveis por alguns estigmas periféricos e manifestações neurológicas. A mortali-

\section{MANIFESTAÇÕES NEUROLÓGICAS NAS ENDOCARDITES INFECCIOSAS}

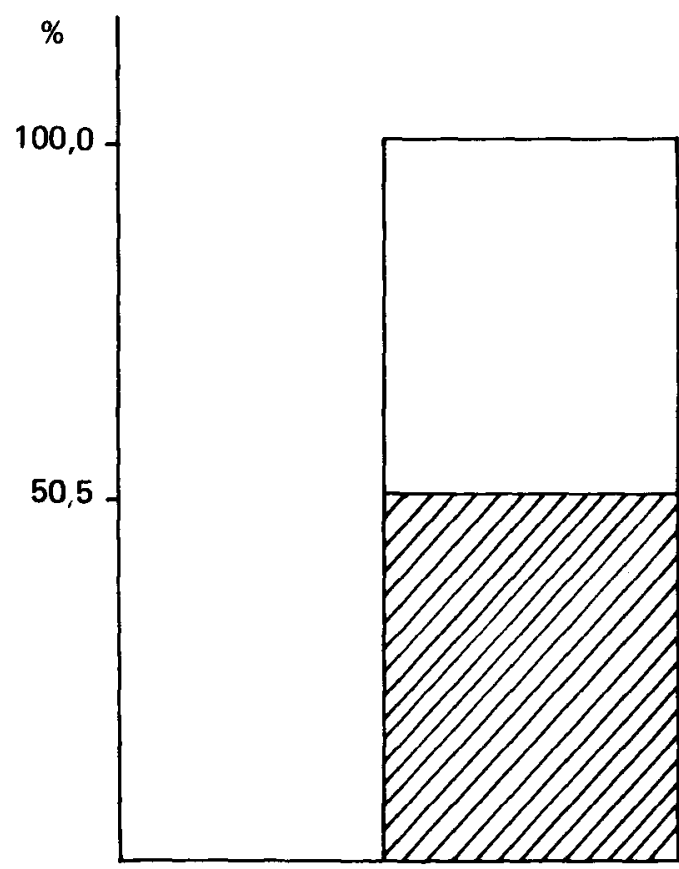

MATERIAL:

Total de casos - 103

HSE - Período de 1947 a 1978

HESS - Período de 1975 a 1978

Casos com Manifestações Neurológicas

Totalizaram $52(50,5 \%)$ 
dade nestes grupos foi também muito elevada e apenas 5 de 19 sobreviveram, mostrando quão agudos, traiçoeirose graves são estes espectros clínicos de endocardites. $O$ ecocardiograma é um exame auxiliar de recente aquisição que poderá ser bastante útil na ajuda ao diagnóstico nas endocardites infecciosas, principalmente se manipulado com aspectos clínicos gerais do enfermo. E claro que, isolada. mente, tem limitações e poderia oferecer informes às vezes falsos, tais como resultados falso-positivos ou falso-negativos ${ }^{24}, 53$.

\section{MORTALIDADE COMPARATIVA DOS CASOS DE ENDOCARDITE INFECCIOSA COM E SEM MANIFESTAÇÕES NEUROLOGICAS}

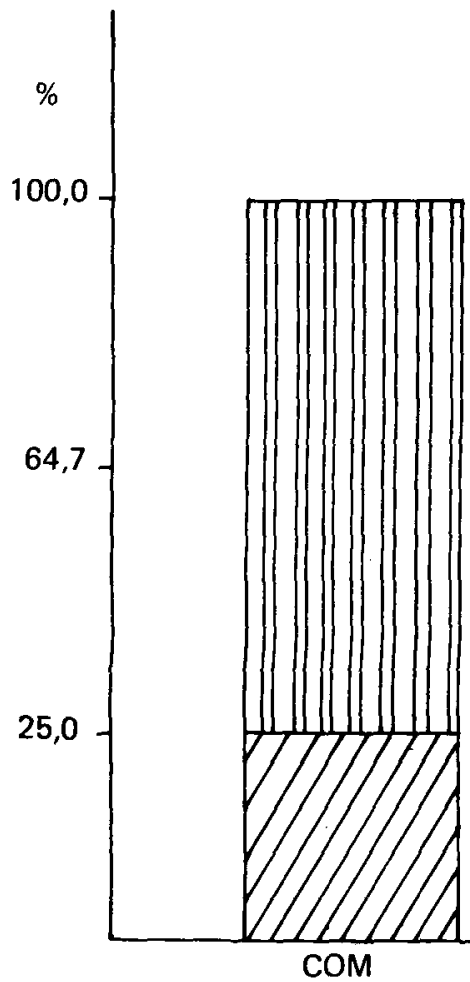

52 Casos com Alt. Neurológicas

Obito: $39-75 \%$

Alta: $\quad 13-25 \%$

51 Casos sem Alt. Neurológicas

Obito: $18 \quad 35,3 \%$

Alta: $33-64,7 \%$

DISTRIBUIÇÃO DA IDADE E SEXO EM PACIENTES COM ENDOCARDITE INFECCIOSA COM MANIFESTAÇÕES NEUROLÓGICAS

\begin{tabular}{|c|c|c|c|c|}
\hline IDADE(anos) & Masc. & Fem. & TOTAL & $\%$ \\
\hline Abaixo de 10 & 4 & 2 & 6 & 11,5 \\
\hline $10-19$ & 9 & 3 & 12 & 23,1 \\
\hline $20-29$ & 7 & 6 & 13 & 250 \\
\hline $30-39$ & 2 & 2 & 4 & 7,7 \\
\hline $40-49$ & 2 & 2 & 4 & 7,7 \\
\hline Acima de 50 & 9 & 4 & 13 & 25,0 \\
\hline TOTAL & 33 & 19 & 52 & 100,0 \\
\hline$\%$ & 63,5 & 36,5 & 100 & \\
\hline
\end{tabular}




\section{CRITERIOS DIAGNÓSTICOS DE ENDOCARDITE INFECCIOSA}

A) Lesão Cardiaca - Febre - Hemocultura Positiva

B) Lesão Cardíaca - Febre - Hemocultura Positiva - Tromboembolismo

C) Lesão Cardíaca - Febre - Hemocultura Negativa - Tromboembolismo

D) Bacteremia - Aparecimento de Sopro Organico - Anemia

E) Achados exclusivos de necropsia

F) Septicemia - Aparecimento de sopro orgânico - Anemia - Alterações Ecocardiográficas

G) Septicemia - Anemia - Manifestações Neurológicas - Tromboembolismo Periférico (Vasculite Infecciosa) - Alterações Ecocardiográficas (este critério é válido nas formas agudas da doença)

H) Septicemia - Anemia - Aparecimento de sopro orgânico - Comprovação cirúrgica indicada para corrigir distúrbios hemodinâmicos ou infecções incontroláveis.

\begin{tabular}{|c|c|c|c|}
\hline \multicolumn{4}{|c|}{ INCIDÉNCIA DAS MANIFESTAÇÖES NEUROLÓGICAS ENCONTRADAS } \\
\hline ESPECIFICAÇÃO & NOP & E CASOS & $\%$ \\
\hline Sinais de Irritação Meningeia & & $25 / 52$ & 48,1 \\
\hline Alteração de Comportamento & & $20 / 52$ & 38,4 \\
\hline Paralisias e Paresias & & $20 / 52$ & 38,4 \\
\hline Coma & & $18 / 52$ & 34,6 \\
\hline Torpor & & $17 / 52$ & 32,7 \\
\hline Cefaléia & & $16 / 52$ & 30,7 \\
\hline Comprometimento de Pares Craneanos & & $14 / 52$ & 26,9 \\
\hline Convulsões & & $10 / 52$ & 19,2 \\
\hline Afasia & & $7 / 52$ & 13,5 \\
\hline Alterações de Fundo de Olho & & $7 / 52$ & 13,5 \\
\hline Comprometimento de Medula ou N. Periférico & & $4 / 52$ & 7,7 \\
\hline Tremores & & $3 / 52$ & 5,8 \\
\hline Disartria & & $3 / 52$ & 5,8 \\
\hline Amaurose Bilateral & & $1 / 52$ & 1,9 \\
\hline \multicolumn{4}{|c|}{ RELAÇÃO ENTRE ALTERAÇÃO NEUROLÓGICA E MORTALIDADE } \\
\hline ESPECIFICAÇÃO & NO DE CASOS & & $\%$ \\
\hline Coma & $15 / 18$ & & 83,3 \\
\hline Torpor & $14 / 17$ & & 82,5 \\
\hline Comprometimento de $\mathrm{N}$ Craneanos & $11 / 14$ & & 78,5 \\
\hline Alterações do Comportamento & $15 / 20$ & & 75,0 \\
\hline Convulsões & $7 / 9$ & & 66,6 \\
\hline Sinais de Irritação Meningeia & $16 / 24$ & & 66,6 \\
\hline Alterações Motoras & $12 / 19$ & & 63,2 \\
\hline Afasia & $4 / 7$ & & 57,1 \\
\hline Amaurose Bilateral & $1 / 1$ & & \\
\hline
\end{tabular}

É difícil um estabelecimento direto entre as manifestações neurológicas e o prognós tico, desde que frequentemente são múltiplas ou pelo menos mais de uma em um mesmo paciente. O que não nos deixa dúvida, no entanto, é que nas endocardites, quando existem alterações neurológicas tanto na esfera orgânica quanto funcional, a mortalidade é mais elevada. 


\section{GERMES ISOLADOS EM CASOS DE ENDOCARDITE INFECCIOSA} COM MANIFESTAÇÕES NEUROLÓGICAS

\begin{tabular}{lcc}
\hline \multicolumn{1}{c}{ GERMES } & No DE CASOS & $\%$ \\
\hline Staphylococcus aureus & 13 & 68,4 \\
Streptococcus viridans & 2 & 10,5 \\
Diplococcus pneumoniae & 1 & 5,25 \\
Escherichia coli & 1 & 5,25 \\
Candida albicans & 2 & 10,5 \\
\hline TOTAL & 19 & 100,0 \\
\hline
\end{tabular}

MATERIAL: Sangue (14)

Líquido Pericárdico (1)

Líquor (4)

\section{MORTALIDADE EM RELAÇÃO AO AGENTE ETIOLÓGICO}

\begin{tabular}{lcc}
\hline \multicolumn{1}{c}{ GERMES } & NO DE CASOS & $\%$ \\
\hline Staphylococcus aureus & $10 / 13$ & 76,9 \\
Streptococcus viridans & $1 / 2$ & - \\
Diplococcus pneumoniae & $1 / 1$ & - \\
E. coli & $1 / 1$ & - \\
Candida albicans & $1 / 2$ & 50,0
\end{tabular}

O Estafilococo Áureo foi o germe mais encontrado em nosso material associado geralmente às formas agudas e destrutivas de infecção endocárdica e à presença de manifestações neurológicas tais como meningoencefalite, infarto, hemorragia encefálica e abscessos cerebrais.

\begin{tabular}{|c|c|c|}
\hline \multicolumn{3}{|c|}{ ACHADOS NEUROPATOLOGICOS EM 15 CASOS DE NECROPSIA } \\
\hline & \multicolumn{2}{|c|}{ COM ENDOCARDITE INFECCIOSA } \\
\hline LESÃO & NO DE CASOS & $\%$ \\
\hline Meningite & $10 / 15$ & 66,5 \\
\hline Encefalite & $9 / 15$ & 60,0 \\
\hline Infarto Encefálico & $8 / 15$ & 53,3 \\
\hline Hemorragia Cerebral & $8 / 15$ & 53,3 \\
\hline Microabscessos & $7 / 15$ & 46,6 \\
\hline Hemorragia Sub-Aracnoideia & 4115 & 26,7 \\
\hline Aneurisma Micótico & $2 / 15$ & 13,3 \\
\hline Hemorragia Cerebelar & $1 / 15$ & 6,6 \\
\hline Ependimite Purulenta & $1 / 15$ & 6,6 \\
\hline Tromboembolismo & $1 / 15$ & 6,6 \\
\hline Vasculite Purulenta & $1 / 15$ & 6,6 \\
\hline Hérnia de Hipocampo e Supracalosa & $1 / 15$ & 6.6 \\
\hline
\end{tabular}




\section{CONCLUSÕES}

1) Alta incidência de manifestações neurológicas nas endocardites infecciosas: $50,5 \%$

2) Principais síndromes neurológicas:

a) Síndrome de irritação meningeia

b) Encefalopatia tóxica

c) Síndrome cérebrovascular

d) Alterações do nível de consciência (torpor e coma)

3) As manifestações neurológicas podem constituir:

a) Quadro clínico inicial principal

b) Complicação evolutiva importante

4) A associação de endocardite infecciosa e manifestações neurológicas implicam em pior prognóstico.

5) Alterações neurológicas relacionadas com pior prognóstico:

a) Coma e torpor

b) Comprometimento de nervos craneanos

c) niterações do comportamento

d) Sinais de irritação meningeia e convulsões

e) Alterações motoras

6) As alterações neurológicas, tanto clínicas quanto anátomopatológicas, são frequentemente múltiplas em um mesmo paciente.

7) $O$ elevado índice de manifestações neuropsiquiátricas observado na análise de nosso material foi em parte consequente aos pacientes admitidos no H.E.S.S. Dos 103 protocolos levantados, 19 foram nesse hospital admitidos com o diagnóstico de meningoencefalite.

8) Todo paciente com manifestações neurológicas e com febre, a endocardite infecciosa tem que ser ao menos pensada $e$ pesquisada.

9) Apesar da utilização dos chamados critérios mínimos, a doença às vezes passa sem reconhecimento, sendo somente diagnosticada pela necropsia.

10 Os critérios clássicos para o diagnóstico da endocardite infecciosa permanecem válidos, porém, os avanços tecnológicos $\mathrm{e}$ as modificações dos padrões clínicos e etiológicos da doença, farão com que modificações naqueles critérios sejam realizadas.
11) As alterações liquóricas mais comuns são: liquor claro ou turvo com pleocitose e domínio de polimorfonucleares, proteínas elevadas e presença de hemáceas em muitos desses casos. Liquor francamente purulento pode ser observado mas não é o comum. $O$ agente etiológico pode ser identificado no liquor através de bacterioscopia ou cultura, como ocorreu em alguns de nossos casos em relação ao estafilococo aureo.

12) O diagnóstico da doença é essencialmente clínico, mas a comprovação bacteriológica tem que ser tentada sempre.

13) A incidência de hemoculturas negativas em nosso material foi alta em consequência principalmente da utilização prévia de antimicrobianos e carência das técnicas microbiológicas.

14) A etiologia das endocardites infecciosas vem se modificando nos últimos anos em consequência dos avanços tecnológicos médicos, modificações dos padrões sociais do homem, e, entre nós, as formas agudas produzidas por estafilococos estão diretamente relacionadas aos baixos padrões sócio-culturais, higiênicos e econômicos de nosso povo.

15) Estafilococo aureo foi o agente etiológico mais encontrado, associado a elevada mortalidade e a processos septicêmicos agudos com destruição de válvulas, principalmente aortica e/ou mitral, presença de meningoencefalite purulenta, infarto, hemorragias encefálicas e abscessos cerebrais.

16) A doença é hoje uma condição cuja terapêutica é clínica e cirúrgica.

17) O controle melhor da taxa de mortalidade nesta doença deve envolver um grande es. forço clínico, laboratorial e até mesmo cirúrgico.

18) A mortalidade da doença continua alta a despeito do número elevado de antimicrobianos disponíveis na atualidade.

19) As causas mais comuns de morte nesta enfermidade são a falta de domínio do quadro infeccioso e as alterações hemodinâmicas severas decorrentes de processos destrutivos valvulares, principalmente mitral e aórtico, conduzindo os pacientes ao óbito por falência cardíaca incontrolável. 
20) A agressão ao sistema nervoso através de processos vasculares, infecção meningoencefálica com edema cerebral, abscesso único ou abscessos múltiplos, podem ser a causa imediata da morte.

21) Os achados de necropsia mais frequentes foram:
a) Meningoencefalite purulenta
b) Infarto e hemorragia encefálica
c) Microabscessos
d) Hemorragia sub-aracnoidea.

\section{DISCUSSÃO}

Sendo infecções que atingem estruturas intravasculares, as manifestações clínicas são potencialmente dirigidas para múltiplos sistemas, ora dominando num, ora noutro; às vezes podem ocorrer manifestações isoladas, pouco comuns e até mesmo bizarras. Sendo proteiforme em suas exteriorizações e sendo capaz de imitar doenças primitivas de outros órgãos ou sistemas, a melhor política do médico internista em relação a esta traiçoeira infecção é ter sempre sua possibilidade em mente e um al to grau de suspeita clínica $46,40,21,58,11,14,31$, $43,60,61,26,59,62,28,52,54,18,37,32$

A endocardite ocasionada por germes pouco agressivos tais como os estreptococos viridans, usualmente se exterioriza por febricula, adinamia, astenia, palidez cutâneo-mucosa, anorexia, perda de peso, manifestações articulares geralmente discretas, sintomas estes que podem cursar semanas e até mesmo meses antes que o paciente procure serviços médicos. Estes enfermos têm quase sempre alterações cardíacas detectáveis ao exame físico e que chamam a atenção do médico alertando para a doença. Os fenômenos de tromboembolismo, quando surgem no início do quadro infeccioso, caracterizam melhor a natureza do quadro febril. No entanto, podem os pacientes cursar um longo tempo sern que os mesmos apareçam, e não deve o internista esperar por estas manifestações para pensar no diagnóstico. A suspeita e a terapêutica devem vir muito antes destas manifestações $46,40,21,58,11,31,60,61$, $41,26,62,28,52$

Outro espectro clínico da doença é o representado pelas formas agudas, que cursam de maneira mais ostensiva, dramática e, às vezes, com alterações enganadoras, tais como ausência de sopros cardíacos, presença de fenômenos tromboembólicos pulmonares, ou alterações neurológicas importantes. Entre estes dois espectros da doença, outros quadros clínicos podem ser notados, mostrando a complexidade e quão enganadora pode ser a enfermidade. Outras características que tornam o problema mais complexo são modificações observadas por exemplo nos padrões da doença, associados ao uso ilegal de drogas, as endocardites pós-cirurgia cardiovascular, as endocardites dos pacientes com "shunt" para hemodiálise, as endocardites em pacientes imuno-deprimidos, e o aumento da incidência da doença em pessoas idosas. Passo a passo, deve o internista acompanhar estas modificações de padrões clínicos e etiológicos, para uma melhor compreensão do diagnóstico e da terapêuti-

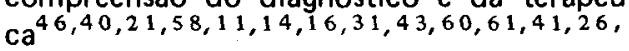
62,54

Os estigmas periféricos da entidade, quando presentes, sẫo de alto valor clínico para o diagnóstico, embora não patognósticos. As petéquias têm sido encontradas em torno de 20 a $40 \%$ e são mais comuns nas formas de longo curso. Tém localizações preferenciais nas conjuntivas, palato, mucosa oral e extremidades e, talvez sejam produzidas por microêrnbolos, ou sejam expressão de vasculite tóxica, ou ainda de natureza imunológica. As hemorragias em 'splinter" sub-ungueais em quirodáctilos ou pododáctilos, que adquirem grande valor diagnóstico quando encontradas em pacientes febris e com soprologia ou quando novas tornam a surgir enquanto o paciente está sob observação, devem ser procuradas com insistência. A mancha de Roth ou sinal de Roth, que aparece com freqüência baixa, em torno de 3 a $5 \%$, e que talvez, se procurada sistematicamente não ocorresse em cifras tão pequenas, é caracterizada pela presença de lesões pálidas, ovalares, na retina, usualmente perto do disco óptico, circundadas por área de hemorragia. Os nódulos de Osler são lescas intra-cutâneas que aparecem mais comumente nas extremidades (palma das mãos, sola dos pés, extremidades dos dedos das mãos e dos pés) e que vão desde 2 a $15 \mathrm{~mm}$ de diâmetro, firmes, avermelhados e dolorosos. Podem, em sua evolução, descamar e até mesmo ulcerar em raras ocasiões. Talvez sejam também lesões de vasculite imunológica ou tóxica; no entanto, a possibilidade de micro-trombo não está excluida definitivamente. Ocorrem em torno de 10 a $25 \%$ dos casos de endocardite e são raramente vistos nas formas agudas da condição. As lesões de Janeway, quase que exclusivamente presentes nas formas agudas, principalmente de etiologia estafilocócica, se 
caracterizam pela presença de máculas e hemorragias nas palmas das mãos e em planta dos pés, e não são dolorosas como os nódulos de Osler. $O$ vaqueteamento dos dedos pode ser observado nas formas de longa evolução, podendo desaparecer com o tratamento. Geralmente a palidez dos dedos é também constante hemorragias em "splinter" também são observadas nesta situação.

Os distúrbios trombo-embólicos têm diminuído com a terapêutica antimicrobiana, desde que o diagnóstico tenha sido também relativamente precoce. São mais comuns para o baço, rins, sistema nervoso, artérias coronárias, pulmões (principalmente nas endocardites do lado direito), artérias retinianas e para os vasos das extremidades superiores e inferiores principalmente. São representadas, estas alterações, por fragmentos de vegetações infectadas que se desprendem das válvulas e caem na circulação dando origem aos processos oclusivos ou ao aparecimento de aneurismas micóticos.

Trabalhos mostrando as alterações e a importância dos achados neurológicos têm saido de forma sistemática nos últimos anos, e, revisões extensas sobre o assunto têm também sido feitas e serão comentadas a seguir. Especulações a respeito da incidência das alterações neurológicas, frequência das mesmas no passado e na era atual, principais distúrbios neurológicos, importância no diagnóstico e prognóstico, história natural das lesões e condutas diagnósticas a serem consideradas, assim como aspectos terapêuticos que poderão advir ou que se fazem necessários são bastante comentados.

Em estudo extenso e atual, Amy Pruitt e cols $^{44}$ fazem a análise de 218 pacientes com endocardite bacteriana que foram hospitalizados no Massachusetts General Hospital, de 1964 a 1973. As conclusõ̃es principais destes autores foram: 1) as complicações neurológicas permanecem um importante problema nas endocardites infecciosas; 2) de 218 casos de endocardite, 84 (39\%) tiveram uma complicação neurológica e $58 \%$ destes 84 pacientes morreram. De outro lado, a taxa de mortalidade foi de apenas $20 \%$ entre aqueles pacientes com endocardite sem manifestação neurológica; 3) das complicações neurológicas, o embolismo cerebral foi a mais frequente e importante, sendo observado em $37(37 \%)$ dos pacientes e destes, 30 faleceram. As alterações embólicas foram importantes nãio somente em termos de morbidade e mortalidade que ocasionaram através dos infartos cerebrais, mas também na patogenia e causa de aneurismas micóticos, abscessos cerebrais e alterações liquóricas. Os germes mais frequentemente envolvidos nas embolias cerebrais foram os estafilococos áureos e gram-negativos da flora entérica, e a infecção da válvula mitral foi a mais importante.

Pruitt e cols ${ }^{44}$ deram ênfase ainda a outros fatos como: a incidência de aneurismas micó. ticos é maior nas endocardites agudas do que mais tarde no curso das formas sub-agudas; a cicatrização destes aneurismas pode ocorrer com o tratamento, portanto eliminando em alguns pacientes a necessidade de uma intervenção neuro-cirúrgica; o tratamento dos aneurismas micóticos demonstrados pela angiografia depende da presença ou ausência de hemorragia, localização anatômica e curso clínico da doença. Registraram ainda que: o abscesso cerebral macroscópico é uma complicação rara da endocardite bacteriana; os abscessos miliares são mais comuns que os grandes, particularmente com doença aguda e infecção miliar em outras estruturas orgânicas; convulsão focal ocorre mais comumente em pacientes com endocardite, com doença aguda embólica, e convulsões generalizadas nestes casos são mais ligadas a distúrbios metabólicos, e naqueles casos com insuficiência renal a neurotoxicidade por infusão maciça de penicilina deve ser pensada; finalmente, registraram que a punção lombar pode refletir a natureza do agente etiológico melhor do que a natureza da complicação neurológica, e que a endocardite produzida por $S$. aureus é usualmente associada com uma fórmula liquórica purulenta, enquanto os estreptococos viridans usualmente fornecem um líquor asséptico ou normal.

Irwim Ziment ${ }^{59}$ fez em 1969 uma extensa revisão numa tentativa de classificação dos aspectos clínicos e patológicos das complicações do sistema nervoso central nas endocardites bacterianas, numa tentativa prática de fornecer elementos para o diagnóstico. Para isto, reviu o autor as maiores séries de endocardites infecciosas assinaladas na literatura de língua inglesa, nas quais as características neurológicas foram claramente descritas. Sumariza dizendo que as complicações neuro-psiquiátricas são comuns nas endocardites bacterianas e, se pesquisadas, podem ser encontradas em 40 a 50 por cento dos pacientes. Friza que o sistema nervoso é envolvido tão frequentemente na presente era como nas décadas anteriores à 
introdução dos antibióticos. Qualquer síndrome psiquiátrica ou neurológica de caráter agudo que surge em um paciente febril e com sopro cardíaco, na ausência de arritmia, deve sugerir ao médico o diagnóstico de endocardite. As complicações são devidas principalmente às embolias sépticas. A meningoencefalite é a mais comum complicação, porém os fenômenos embólicos e os aneurismas micóticos não são raros. Os abscessos cerebrais são mais frequentes nas formas agudas de endocardite bacteriana do que nas sub-agudas e, na era antimicrobiana tal complicação tem sido menos observada. Outras complicações patológicas menos caracterizadas foram os micro-infartos cerebrais, edema, púrpura, assim como processos de endarterites com tromboses ou estenoses.

Prosseguindo, Ziment chama a atenção para os amplos aspectos clínicos que podem ser observados decorrentes das lesões cerebrais, dos quais os mais dramáticos são a hemiplegia, afasia, paralisias de nervos craneanos, hemorragia cerebral ou sub-aracnoidea. Sintomas relativamente menores, tais como cefaléia ou confusão mental podem carrear um prognóstico sério. O líquor cérebro-espinhal frequentemente demonstra anormalidades que se seguem a embolização cerebral. Ainda que o achado de meningite estéril seja o mais comum, uma lesão subjacente mais grave poderá estar presente; em particular, um aneurisma micótico poderá exteriorizar-se através de uma meningite estéril com poucas ou nenhuma hemácea no líquor. Comenta ainda que uma completa investigação de uma meningite asséptica, no curso das endocardites bacterianas, deverá incluir uma angiografia cerebral, desde que aneurismas micóticos frequentemente poderão ser ressecados. Finaliza suas considerações dizendo que, em geral, as complicações neurológicas não necessitam cuidados especiais diferentes do tratamento da endocardite bacteriana, mas o tratamento neuro-cirúrgico poderá se fazer necessário nos aneurismas micóticos ou nos abscessos cerebrais.

Harrison e Hampton ${ }^{24}$, fazendo revisão de 116 casos de endocardite bacteriana, mostraram que complicações neurológicas ocorrem em um terço da série. Dos 116 pacientes, 33 se hospitalizaram por problemas neurológicos e criaram problemas relativos ao diagnóstico diferencial. Em 22, os sintomas neurológicos foram os primeiros a aparecer. $\mathrm{Na}$ admissão ao hospital, 15 pacientes necessitaram diag- nóstico diferencial com acidente vascular cerebral; 7 com meningite ou meningoencefalite; e 6 com estado tóxico, confusional e delírio. Dos sete casos que se internaram com o diagnóstico de meningite, em 5 o diagnóstico de endocardite foi feito somente à necropsia. Duas características nas endocardites chamaram a atenção desses autores: a) os estafilococos foram responsáveis por uma alta incidência de casos; b) alta incidência de hemoculturas negativas. Tais fatos ocorreram com grande similaridade em nosso material apresentado.

Robert Siekert ${ }^{49}$, da Mayo Clinic, comenta que as manifestações neurológicas podem ocorrer em cerca de $1 / 4$ a $1 / 3$ dos pacientes com endocardite bacteriana. Diz que nenhuma destas manifestações são típicas da doença básica e os guias fundamentais para o diagnóstico da endocardite estão em uma análise completa clínico-laboratorial. Exceção existiria nas alterações de fundo de olho, vistas em cerca de 1 em cada 5 pacientes.

Aspectos também idênticos relativos ao diagnóstico diferencial das meningites e meningoencefalites é levantado por Carpenter e Petersdorf $^{10}$, analisando o espectro clínico destas infecções neurológicas. Fatos análogos relativos às manifestações neurológicas nas endocardites infecciosas são também levantados por Ray ${ }^{47}$, Smith ${ }^{50}$, Harris ${ }^{23}$, Austrian ${ }^{3}$, Bergen $^{7}$, Cooper ${ }^{14}$, Jones ${ }^{29}$, Rabinovich ${ }^{46}$, Pankey $^{40}$, Pankey ${ }^{4} 1$, Vogler ${ }^{58}, K^{\prime}$ Kaye $^{26}, \mathrm{Zi}^{\prime}$ ment $^{59}$, Bawa ${ }^{5}$, Kerr $^{28}$, Thayer ${ }^{2}$, Siekert ${ }^{49}$. Claude e Oury ${ }^{12}$, Tompsett, R. ${ }^{54}$, Toone ${ }^{56}$, Krinske $^{29}$, De Jong ${ }^{15}$, Kernohan ${ }^{2} 7$, Bademo$\mathrm{si}^{4}, \mathrm{Neal}^{38}$.

Royden Jones e cols ${ }^{25}$ registraram que $29 \%$ dos pacientes (110 em 385) com endocardite bacteriana tiveram envolvimento neurológico. Em 60\% (65 em 110 pacientes) o achado neurológico foi, ou a queixa principal ou um dos mais importantes sintomas. Lesões cérebro-vasculares foram registradas em $50 \%$ (55 de 110) dos casos, e sintomas isquêmicos transitórios precederam ao acidente vascular cerebral mais grave em 15 de 55 (27\%) pacientes. Outros achados neurológicos incluídos pelos autores foram: encefalopatia tóxica, meningite, cefaléia orgânica, mononeurites, convulsões e distúrbios visuais. Em alguns casos o diagnóstico inicial não foi endocardite bacteriana, e sim doença neurológica primária ou doença sistêmica. A mortalidade foi de $50 \%$ (55 em 110), sendo 1,6 vezes maior 
do que a esperada em série de enfermos com endocardites.

Eulo Lupi e cols ${ }^{33}$, em estudo de 367 pacientes com endocardites bacteriana estudados no Instituto Nacional de Cardiologia do México, evidenciaram que $7 \%$ dos enfermos exibiram manifestações neurológicas durante o curso da doença, e que alterações neurológicas foram responsáveis por $16 \%$ das mortes. Em alguns casos, as alterações neurológicas são as primeiras manifestações de endocardite bacteriana e podem ser causa de erros diagnósticos. Chamam também a atenção para o fato de que em pacientes adultos jovens com doença cardíaca, febre e manifestações neurológicas ou psiquiátricas, o diagnóstico da endocardite infecciosa deverá ser suspeitado. Os achados patológicos encontrados foram: hemorraria cerebral e infarto e, em casos isolados, neuropatia periférica e neurotoxicidade à penicilina. Terminam os comentários enfatizando que devido à alta incidência de hemorragia cerebral e tendência ao sangramento nesta doença, os anticoagulantes não deverão ser usados; e que a incidência dos transtornos neurológicos resulta em cifras mais elevadas quando procurados com cuidado.

Hernándes Lahoz e cols ${ }^{30}$, revisando 24 casos de endocardites bacterianas no Serviço de Cardiologia del Hospital General de Asturias num período de cinco anos, encontraram $13 \mathrm{com}$ problemas neurológicos objetivos, excluindo manifestações subjetivas tais como cefaléia, vertigens, etc... Os achados principais foram: hemiplegias $(10 / 13)$, síndrome meningeia (9/13), convulsões $(7 / 13)$ e paralisias periféricas (1/13). Deste relato, os autores tiraram algumas conclusões, tais como: a) as complicações cerebrais no curso das endocardites são frequentes e podem ser tardias ou a primeira manifestação grave de um qua. dro de evolução quase que sub-clínico. As lesões neurológicas, podem ser múltiplas em um mesmo enfermo, mas a mais comum foi a lesão motora; b) o quadro neurológico não pode decidir o diagnóstico da doença básica; c) abscesso cerebral não foi encontrado em nenhum caso e atribuem os autores ao fato de que as endocardites por eles estudadas eram as subagudas, produzidas por estreptococos viridans, germe de pouca agressividade para produzir abscesso; d) as lesões a distância podem ser explicadas por arterite, desde que a endocardite não é apenas uma doença do endocárdio, e sim doença do sistema vascular, incluindo as paredes arteriais; e) as arterites seriam lesões importantes em algumas patologias encontradas nesta doença; f) hemorragias cerebrais foram encontradas em todas as necropsias realizadas nesse trabalho, e explicadas pela tendência hemorrágica observada nas endocardites.

Bademosi e cols ${ }^{4}$, em Ibadan na Nigéria, encontraram em $38 \%$ dos pacientes com endocardite infecciosa (36 de 95), manifestações neuropsiquiátricas. $\mathrm{Em} 75 \%$ (27 de 36 ) essas alterações foram as que dominaram o quadro clínico. As alterações neurológicas mais im. portantes foram as cérebro-vasculares, observadas em 15 pacientes (42\%), e meningite, vista em 7 pacientes (19\%). Encefalopatia tóxica $(12,5)$ não foi um achado raro. Outras manifestações neurológicas observadas foram psicose e lesões da medula espinhal. A mortalidade foi elevada, especialmente nas formas agudas de endocardite, refletindo exatamente a nossa experiência e pensamento- Terminam os autores africanos chamando a atenção que é essencial a procura de uma doença cardíaca subjacente em pacientes que apresentam sintomas neuro-psiquiátricos, porque o tratamento da doença de fundo melhora o prognóstico. Comentam ainda que o padrão etário da doença naquela região do mundo é mais baixo do que o observado nos países desenvolvidos, coincidindo também com a nossa experiência. Afirmam ainda que observaram baixa positividade nas hemoculturas, também por nós observada, refletindo principalmente a utilização prévia de antimicrobianos, condições técnicas bacteriológicas precárias e técnicas de cultura não adequadas.

Em conferência clínico-patológica ${ }^{13}$ é mostrado um caso de septicemia estafilocócica com endocardite e abscesso cerebral bastante similar a alguns de nossos casos, onde o que de melhor oferecer ao doente nos deixa em situação difícil. Em alguns casos, a intervenção neuro-cirúrgica se faz necessária para drenagem de abscesso único de grande extensão. Embolia séptica cerebral pode resultar em extensão do processo supurativo junto às estruturas perivasculares, com formação de múltiplos micro-abscessos ou encefalite ${ }^{15}, 27,59$. Clinicamente, os micro-abscessos podem não dar características de sua presença e, mesmo na patologia, às vezes necessițam de uma procura cuidadosa para serem detectados ${ }^{59}$. Os grandes abscessos, que apresentam um sério problema clínico ao médico e ao paciente, ocorrem mais frequentemente nas endocardites agudas, especialmente as produzidas por estafilococos aureos, onde às vezes múltiplos 
pequenos abscessos podem também ser observados $^{2} 2,59,15,27,13$. A presença de abscessos cerebrais nas formas lentas de endocardites é rara mas podem existir, como assinalado por Rabinowitz e cols ${ }^{45}$.

Pankey 40,41 , em seus estudos clássicos sobre endocardites, feitos no Centro Universitário de Minnesota no período de 1939 a 1959 , encontrou uma incidência de 1,2\% 12 casos em 167) de abscessos nas endocardites subagudas, e de pelo menos $24 \%$ (13 casos em 54) de abscessos nas formas agudas de endocardite. Meade ${ }^{34}$ encontrou 20 casos de abscessos em uma série de 109 pacientes (incidência de $18 \%$ ) com endocardites por estafilococo aureo. Kernohan e cols ${ }^{27}$, na Clínica Mayo em 1939, fazendo uma revisão das endocardites agudas encontraram múltiplos abscessos em 9 de 10 casos de necropsias. Gates e cols ${ }^{22}$ encontraram, em extensa revisão feita na Clínica Mayo no periodo de 1915 a 1945 acerca de abscessos cerebrais metastáticos, que de 179 casos de endocardites que foram à autópsia, 15 tinham abscessos cerebrais, o que significa um achado de $8 \%$. Desse estudo, ficou demonstrado que, em 14 dos 15 pacientes os abscessos eram múltiplos.

Lerner e Louis Weinstein ${ }^{31}$, assinalaram apenas um caso de abscesso em 100 de uma série de endocardite. Harry Dowling e cols ${ }^{18}$ encontraram um abscesso cerebral em uma série de 25 endocardites bacterianas agudas por estafilococos. Pruitt e cols ${ }^{44}$, em recente estu do, encontraram uma incidência de $4,1 \%$ em uma série de 218 pacientes, ou seja, 9 casos de abscessos cerebrais na autópsia. O diagnóstico não foi feito em vida em nenhum dos pacientes. Eram predominantemente micro-abscessos e não tinham expressão clínica, estando ainda associados a abscessos miliares em outros órgãos.

Em nossa série ora apresentada, 7 de 15 casos de necropsia tinham micro-abscessos cerebrais. Estes aspectos são importantes desde que os pacientes com endocardite que exibiram manifestações clínicas de lesão que ocupa espaço, uma investigação neurológica completa, incluindo estudos angiográficos e tomografia computorizada, deverá ser realizada no intuito de vislumbrar perspectivas terapêuticas cirúrgicas nos casos de abscesso volumoso de drenagem. Já a terapêutica dos micro-abscesșos é realizada através de antibioticoterapia maciça, igual portanto ao tratamento da doença básica ${ }^{4,59}$. As embolias cerebrais são as mais comuns complicações neurológicas das endocardites bacterianas. A oclusão embólica de grandes artérias cerebrais com infarto cerebral tem sido relatada em 6 a $31 \%$ dos pacientes com endocardites infecciosas ${ }^{4,59}$. Mais

\section{HSE. HESS - ESTUDO ANATOMO.PATOLÓGICO DE 15 CASOS DE ENDOCARDITE INFECCIOSA INTERNADOS} MO HOSP. SERVIDORES DO ESTADO E HOSP. ESTADUAL SÄO SEBASTIĀO_RJ DE 1947 A 1947

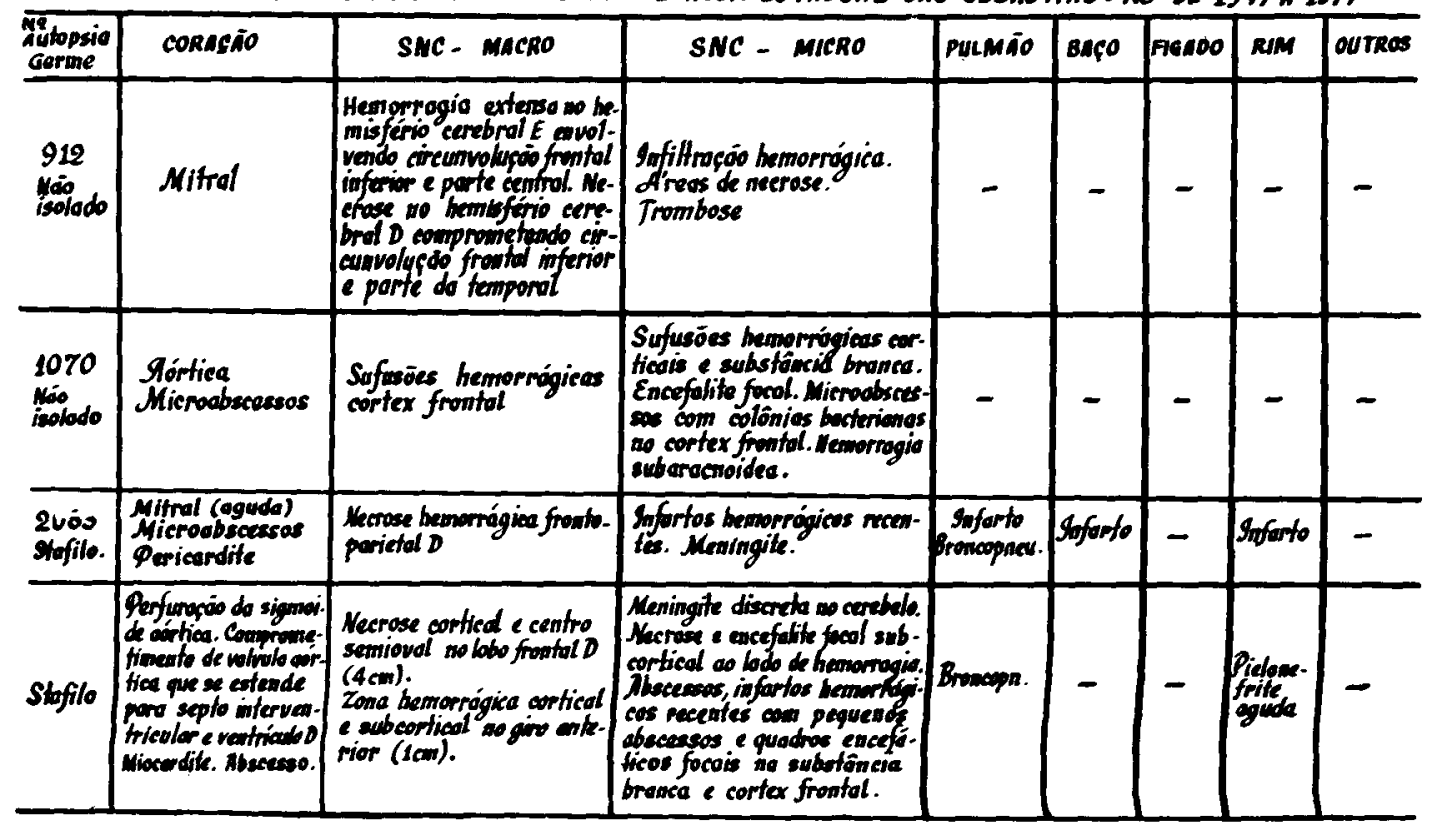


HSE - HESS - ESTUDO ANÁTOMO.DATOLÓGICO DE I5 CASOS DE ENDOCARDITE. INFECCIOSA INTERNADOS NO HOSP. SERVIDORES DO ESTADO E HOSP. ESTADUAL SĀO SEBASTIAO_RJ, DE L 2477 a 1977

\begin{tabular}{|c|c|c|c|c|c|c|c|c|}
\hline $\begin{array}{l}\text { Motópsia } \\
\text { Gervel }\end{array}$ & CORASẼ̃O & SNC - MACRO & SNC - MICRO & PULMй̃o & Bafo & FÍGADO & RUM & outros \\
\hline 4432 & $\begin{array}{l}\text { Tricuspide - Mitrol. } \\
\text { Sórtica }\end{array}$ & $\begin{array}{l}\text { Leptomeninges congestoss. Ne } \\
\text { bose do lobo teonporal a E, pon. } \\
\text { to avermethodo. }\end{array}$ & $\begin{array}{l}\text { Srreas foeais de encefalite. } \\
\text { Meningite. }\end{array}$ & - & Snforto & Soforto & Sofforto & - \\
\hline 4443 & 一 & 一 & $\begin{array}{l}\text { Meningite Enoefolife purylen - } \\
\text { to. Voseulite purulenta. }\end{array}$ & s/laudo & - & - & - & - \\
\hline $\begin{array}{l}4572 \\
\text { Moio } \\
\text { isolodo }\end{array}$ & $\begin{array}{l}\text { Mitral. End Rewnóti } \\
\text { co (Mitral) } \\
\text { Estenase mitrol }\end{array}$ & $\begin{array}{l}\text { Inforto no heminferio D oo } \\
\text { hível dos núckes de buse }\end{array}$ & $\begin{array}{l}\text { Inforto, necrose com micro- } \\
\text { abscessos. Encefalite focal }\end{array}$ & Broucopn. & Suforto & - & Sinfurt & - \\
\hline $\begin{array}{r}5758 \\
\text { bilado } \\
\end{array}$ & Mitral & 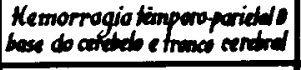 & Sem wiere & - & Safarto & Aicreacs & - & - \\
\hline 5046 & - & 一 & 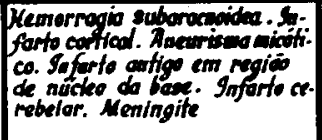 & s/laudo & - & - & - & - \\
\hline $\begin{array}{l}6105 \\
\text { Noto } \\
\text { icolado }\end{array}$ & $\begin{array}{l}\text { Siótion cow edema } \\
\text { Miocandite c/miero. } \\
\text { abseceses. Estewose } \\
\text { mitral. }\end{array}$ & 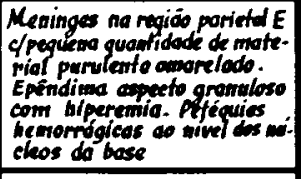 & 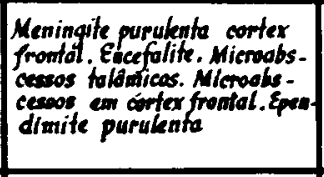 & 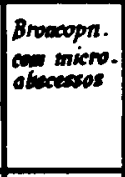 & - & - & 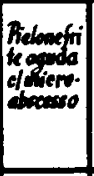 & $\longrightarrow$ \\
\hline 7928 & $\begin{array}{l}\text { Slorto trinispide } \\
\text { Miocurdite }\end{array}$ & Congestoo de leptomearinges & 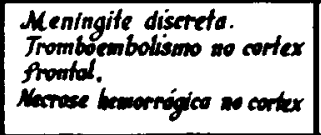 & 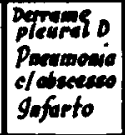 & Iaforto & - & Suforto & 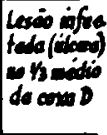 \\
\hline
\end{tabular}

HSE_HESS_ ESTUDO ANÁTOMO_PATOLÓGICO DE 15 CASOS DE ENDOCARDITE IMFECCIOSA IVTERNADOS NO HOSP. SERVIDORES DO ESTADO E HOSP. ESTADUAL SĀO SEBASTTTO_RJ, DE 1947 1977

\begin{tabular}{|c|c|c|c|c|c|c|c|c|}
\hline $\begin{array}{l}\text { Nutopeid } \\
\text { Germe }\end{array}$ & CORASÃO & SNC - MACRO & SNC - MICRO & pulanto & Bafo & flenoo & RIM & outros \\
\hline $\begin{array}{l}6781 \\
\text { stofilo }\end{array}$ & Mitral & 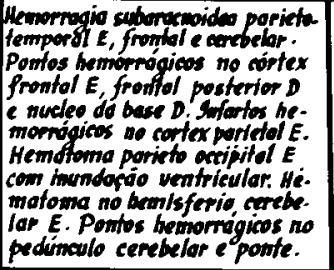 & 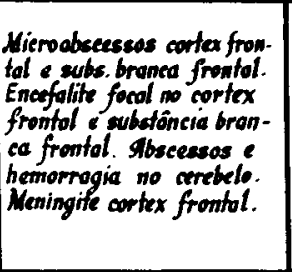 & & $\begin{array}{l}\text { 9oferto } \\
\text { concol. } \\
\text { batérias }\end{array}$ & & & \\
\hline $\begin{array}{l}7744 \\
\text { sfofilo }\end{array}$ & $\begin{array}{l}\text { Endocurdite bacte. } \\
\text { rlone mural } \\
\text { (aur. E). Endarat } \\
\text { dite reumófica } \\
\text { (mitral). } \\
\text { Abscessos }\end{array}$ & 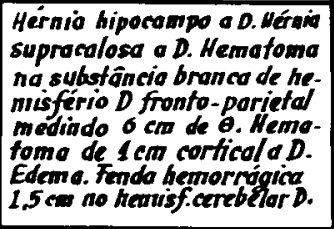 & 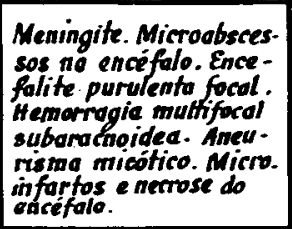 & $\begin{array}{l}\text { Microabs } \\
\text { ceseos. } \\
\text { Broncopn. }\end{array}$ & 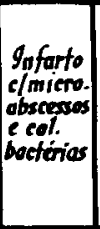 & 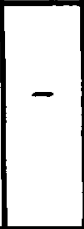 & $\begin{array}{l}\text { Snforto } \\
\text { chimiers } \\
\text { checesses } \\
\text { ecol. } \\
\text { boctínies }\end{array}$ & 一 \\
\hline $\begin{array}{l}7918 \\
\text { stofilo }\end{array}$ & $\begin{array}{l}\text { Aórfica } \\
\text { Miocardite }\end{array}$ & 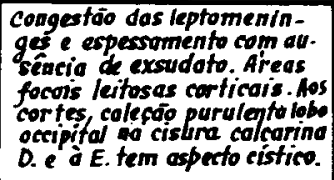 & $\begin{array}{l}\text { Abscesso oceipitol. Miad } \\
\text { abscessogs mulfiplos } \\
\text { corficois. Inforfo cor- } \\
\text { tical. Necrose lominar } \\
\text { corficol. Meaingite } \\
\text { discreta. }\end{array}$ & $\begin{array}{l}\text { Brewcopn. } \\
\text { Derraute } \\
\text { plaurot bi- } \\
\text { latard }\end{array}$ & Soforto & & 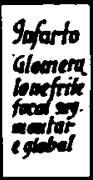 & $\begin{array}{l}\text { Gangras } \\
\text { dapodo- } \\
\text { datilo }\end{array}$ \\
\hline $\begin{array}{l}7359 \\
\text { stafilo }\end{array}$ & $\begin{array}{l}\text { Mitral Pericandite } \\
\text { o wiocandife facsl }\end{array}$ & $\begin{array}{l}\text { Henorragia soberncaoidea } \\
\text { ae Bewifferio } E \text {. }\end{array}$ & San micro & Bromeopa. & Sefarto & - & storto & - \\
\hline
\end{tabular}

ria cerebral média causando hemiplegias, hemiparesias e déficits sensoriais. As manifestações clínicas observadas com os micro-êmbolos são mais diversas, sendo a mais comum, al- mais sugestivos são convulsões e/ou flutuações de sinais neurológicos focais. Os micro-êmbolos podem ser também apenas achados de necropsia sem exteriorização clínica alguma. 
Observações iniciais sugeriam que o embolismo cerebral fosse mais comumente visto nas endocardites bacterianas sub-agudas causadas pelos estreptococos viridans ${ }^{56}$. Morgan e Bland ${ }^{37}$, no entanto, mostraram que a embolia ocorreu em $30 \%$ dos casos com endocardites agudas e somente em $7 \%$ dos que tinham as formas sub-agudas da doença. Tais observações têm também sido nossa experiência com as formas agudas da doença, principalmente com as estafilocócicas, nas quais as manifestações embólicas ocorrem às vezes precocemente, às vezes quase que abrindo o quadro clínico, dando idéias da presença de vegetações múltiplas, grandes e friáveis. Pearce e Guze $^{42}$ em 1961 relataram uma taxa de mortalidade precoce de $67 \%$ em seus pacientes com embolia cerebral, com um total de $75 \%$ falecendo nos primeiros 12 meses após o ataque de endocardite. Rabinovich ${ }^{46}$ assinalou em sua série de 1950 a 1963, que seus pacientes que tiveram embolia cerebral apresentaram mortalidade precoce de $30 \%$, enquanto a taxa de mortalidade nos 5 anos de seguimento chegou a $51 \%$. Estudos modernos feitos através do Echo e do fibrinogênio marcado poderão talvez prever os chamados pacientes de alto risco no que concerne a embolia cerebral no curso de endocardite infecciosa, nos quais tentativas cirúrgicas poderão ser feitas com o intuito de diminuir a mortalidade e morbida$\mathrm{de}^{44}$. Pruitt ${ }^{44}$ enfatiza que, embolia cerebral que ocorre dentro de duas semanas de instalação da infecção endocárdica é associada a germes virulentos, particularmente $\mathrm{S}$. aureo, enterococo e E. coli.

Em nossa série de 52 casos com manifestações neurológicas, 20 apresentaram alterações motoras tipo hemiplegia, hemiparesia, e 14 tiveram alterações motoras de pares craneanos. Dos 15 casos que foram necropsiados, 8 evidenciaram infarto encefálico e 8 hemorraria cerebral. As alterações clínicas ligadas mais frequentemente ao envolvimento de nervos craneanos e também por nós assinaladas, são as que acometeram o II, III, IV e VI e, em raras ocasiões, embolia para a artéria central da retina. Amaurose bilateral foi observada em um paciente nosso com endocardite bacteriana aguda por estafilococo e meningite, que evoluiu para o óbito. As exteriorizações clínicas mais comuns são a diplopia, estrabismo, hemianopsia, e até mesmo perda total ou parcial da visão. As manifestações meningoencefálicas são importantes alterações em alguns casos de endocardite, quer nas formas sub- agudas, quer nas agudas. Nas formas agudas são, em muitas ocasiões, as alterações clínicas que dominam o espectro da doença de base, passando esta desconhecida e recebendo os pacientes os rótulos de "meningoencefalites". A literatura exibe desde longos anos interessantes e importantes trabalhos referentes ao assunto.

Smith $^{50}$, em 1939 já chamava a atenção das meningites secundárias às endocardites sub-agudas bacterianas. Harris ${ }^{23}$ assinala os mesmos aspectos, e Carpenter e Petersdorf ${ }^{10}$, ao fazerem uma análise do espectro clínico das meningites, também chamam a atenção para os mesmos aspectos. Austrian ${ }^{3}$, Bergen e Dermksian $^{7}$, Siekert ${ }^{49}$, Claude' e Oury ${ }^{12}$, $\mathrm{Neal}^{38}$, Bawa ${ }^{5}$, Krinsky ${ }^{29}$, De Jong ${ }^{15}$, Toone ${ }^{56}, K^{\prime}$ Kernohan ${ }^{27}, \operatorname{Lupi}^{33}$, Lahoz ${ }^{30}, \mathrm{Ba}^{\prime}$. demosi ${ }^{4}$, e muitos outros através dos tempos têm enfocado os mesmos achados. Royden Jones, Siekert e Geraci, durante um período de 14 anos (1950 a 1964) na Mayo Clinic, assinalaram meningite aguda em 7 de 110 pacientes com endocardite, e nessa análise afirmaram que todos os pacientes tinham sopro cardíaco e comentam que essa associação (meningite mais sopro cardíaco) é altamente sugestiva de endocardite. Carpenter e Petersdorf ${ }^{10}$, de 209 casos consecutivos de meningite, demonstraram a endocardite como doença primária em 13. Bademosi ${ }^{4}$, de 95 pacientes, assinalou que $7(7,4 \%)$ foram admitidos com o diagnóstico de meningite. Bergen e Dermksian ${ }^{7}$ assinalaram que meningoencefalite é a mais comum complicação neurológica das endocardites agudas e sub-agudas. Meningite purulenta aguda foi a complicação neurológica mais comum assinalada por Lerner e Weinstein ${ }^{31}$. Austrian $^{3}$ e Thayer $^{52}$ comentam também a frequente associação de endocardite penumocócica e meningoencefalite. $\mathrm{O}$ achado de uma meningite estéril, segundo Toone ${ }^{56}$, chama a atenção para o diagnóstico de endocardite bacteriana sub-aguda. Os achados liquóricos vão desde um líquor francamente purulento até a líquor com aspectos normais, com o paciente exibindo sinais meníngeos. Os achados usuais, que têm coincidido com os nossos são: a) pleocitose com domínio de polimorfonucleares; b) presença, muitas vezes, de hemáceas; c) proteínas elevadas; d) bacterioscopia e cultura positivas foram observadas por nós em 4 casos de endocardites agudas estafilocócicas. Os achados de literatura são: a) pleocitose moderada ou elevada; b) aumento de proteínas; c) glicose usualmente normal. Frequen- 
temente, bacterioscopia e cultura são negati$\operatorname{vas}^{44,7,59,38,52,56}$. Amy Pruitt e cols ${ }^{44} \mathrm{fi}$ zeram uma análise do líquor de 69 pacientes em uma série de 84 com manifestações neurológicas num total de 218 com endocardite. Destes 69, 21 não exibiram alterações liquóricas apesar de terem manifestações clínicas. Em 19, o liquor foi purulento (predomínio de polimorfonucleares na pelocitose, glicose baixa e proteínas elevadas). Em 17 pacientes o líquor foi asséptico (pleocitose com predomínio de linfócitos, glicose normal e concentração das proteínas normal ou ligeramente elevada). Em 19 pacientes o líquor foi hemorrágico (mais de 200 hemáceas por $\mathrm{mm}^{3} \mathrm{em}$ todos os tubos). As indicações clínicas mais importantes para a punção lombar, nesta série, foram: a) rigidez de nuca e/ou; b) estado de confusão mental. Em nossa presente série de 103 pacientes estudados, 52 tiveram manifestações neurológicas e destes, 25 exibiram síndrome meningeia (cefaléia, rigidez de nuca, sinais de Kernig, Brudzinski). Destes 25,19 foram admitidos no H.E S.S. com o diagnóstico de meningite e mais tarde comprovou-se através de análise clínica completa (porta de entrada ${ }_{i}$ alterações mucosas e cutâneas, hemoculturas positivas em muitos, líquor com bacterioscopia e cultura positivas para $S$. aureo em 4 e 3 autópsias) que a doença básica era endocardite bacteriana aguda e em todos que pudemos comprovar, a etiologia foi estafilocócica.

Chamamos ainda a atenção para o importante fato, que nessas formas agudas muitos dos pacientes não exibem sopros. Os dados clínicos que nos ajudam mais são: a) porta de entrada cutânea através de furúnculos, abscessos, celulite ou feridas infectadas contendo pus, manifestações de meningite com líquor mostrando pleocitose com domínio de polimorfonucleares, proteínas altas e em alguns casos presença de hemáceas. E 4 dos pacientes, bacterioscopia e cultura positivas para $S$. aureus ocorreram. Outros achados de extrema importância foram a presença, praticamente na totalidade dos casos, dos estigmas periféricos das endocardites agudas, tais como: petéquias conjuntivas, hemorragias em "splinter", sinal de Roth, nódulos de Osler, lesões de Janeway, que são, sem dúvida alguma, de inestimável valor quando presentes. Voltamos a frisar que a soprologia, nessas formas de endocardite bacteriana, em muitos casos não está presente; na maioria deles, surgem na evolução sinais esteto-acústicos de comprometimento da válvula mitral e/ou aórtica: O echo seriado também é importante na ajuda ao diagnóstico dessas formas.

As manifestações meningoencefálicas foram as mais importantes e frequentes alterações neurológicas de nosso estudo. Ao lado das manifestações de encefalopatia tóxica, queda do nível de consciência e síndrome vascular cerebral, foram as que mais nos impressionaram. As manifestações de encefalopatia tóxica ocorrem em um grande número de doenças infecciosas e não são necessariamente associadas a alterações cerebrais patológicas definidas. Podem essas alterações, que compõem amplo espectro clínico da chamada encefalopatia tóxica, serem produzidas pela febre ou toxinas de um modo geral. Tais manifestações às vezes são exuberantes nas salmoneloses, principalmente febre tifóide, leptospiroses, malária e febres maculosas. Nas endocardites infecciosas tais alterações podem ser exibidas e ocorrerem secundariamente a múltiplos êmbolos cerebrais ou vasculite cerebral. E impossível dizermos, do ponto de vista clínico, quais os pacientes que ao apresentarem sintomas de disfunção cerebral, têm lesão or. gânica secundária à endocardite, e quais deles não têm, desde que os sintomas são praticamente os mesmos. Um grande espectro de manifestações psiquiátricas em tais enfermos é conhecido e relatado $2,44,24,25,43,26,59,49$, $28,52,56,29,15,27,33,30,4$. As manifestações da esfera psíquica vão desde pequenas alterações de personalidade, do comportamento e da vigília, até grandes distúrbios como os quadros de agitação psicomotora ou psicoses francas. Bruetsch ${ }^{8}$ reportou os achados de autópsia de 280 pacientes de hospitais de doentes mentais, nos quais encontrou evidência de endocardite em 18 e, em muitas dessas autópsias as alterações cerebrais poderiam ter sido secundárias a endocardites. Fetterman e Ashe $^{19}$ encontraram uma alta incidência de sintomas psiquiátricos numa série de 42 pacientes com endocardite bacteriana sub-aguda. São manifestas mais comumente nos pacientes idosos e, quando presentes, têm um significado de prognóstico pior, podendo nesses enfermos ser as manifestações que dominam toda a cena clínica, como assinalado por Coopera e $\mathrm{cols}^{14}$. Em todos os pacientes febris que apresentam sintomas da esfera psíquica, uma boa ausculta cardíaca deveria ser feita, na procura de soprologia e estigmas periféricos de endocardite. Em nossa série de 52 casos, 20 apresentaram distúrbios do comportamento, e 15 
destes faleceram. E bastante difícil uma correlação imediata, desde que, como previamente assinalado, é comum o achado de vários distúrbios neurológicos em um mesmo paciente.

Os aneurismas micóticos são uma das mais características lesões que complicam a endocardite bacteriana. Embora essas lesões não sejam comuns, o encéfalo é um dos locais mais frequentes de seu aparecimento. São complicações sépticas da doença e que foram reconhecidas por $\mathrm{Osler}^{39}$. Os aneurismas micóticos podem dar origem a hemorragias cerebrais ou a hemorragias sub-aracnoideas, quando se rompem. Esses aneurismas aparecem como consequência do acestamento de um êmbolo séptico no endotélio de um vaso ou no interior de seu vasa vasorum ${ }^{32}$. Podem se instalar uma ou duas semanas após a embolia séptica e ocorrem tanto com os germes de baixa virulência como com os de al ta agressividade. Estes últimos, no entanto, costumam dar origem a meningoencefalites, cerebrites e abscessos cerebrais. Os efeitos compressivos dos aneurismas micóticos podem originar cefaléia, alterações motoras ou podem passar inteiramente assintomáticos ${ }^{4,59}$. Trombose secundária pode ocorrer ao nível do aneurisma, com infarto cerebral ${ }^{44}$. A incidência de aneurismas micóticos sugerida por Cantu e cols oscila em torno de 2,5 a $4,5 \%$ de todos os aneurismas intracraneanos, e esta tem sido a experiência de outros autores como Roach $e$ Drake $^{48}$, Mc Donald e Korb ${ }^{36}$, Mitchell e Angrist $^{35}$, Turnbull ${ }^{57}$, dentre 42 casos de aneurismas cerebrais por ele analisados, encontrou treze de natureza micótica, numa incidência alta de $31 \%$. Os aneurismas micóticos poderão dar origem a catástrofes, tais como hemorragia cerebral aguda ou hemorragia sub-aracnoidea, seguidas de morte. Ao se romperem poderão, no entanto, dar origem a manifestações clínicas menos graves e simular quadros de meningoencefalite a líquor claro. Qualquer artéria cerebral, e até mesmo artérias meningeias, podem ser sede de tais alterações. Usualmente se localizam em zonas de bifurcação das artérias, e no encéfalo mais frequentemente são visualizados nos ramos da cerebral média. Alguns investigadores têm assinalado a presença de múltiplos aneurismas micóticos, tais como Roach e Drake ${ }^{48}$, Toole e Patel ${ }^{55}$. A conduta nos casos de sus: peita de aneurismas cerebrais micóticos deverá envolver a arteriografia cerebral, e o tratamento cirúrgico quando houver chance $1,51,47,48$, $44,6,9,26,59,12$. Pruitt e cols ${ }^{44}$, de 218 paci- entes com endocardite bacteriana, encontraram em 4, aneurismas micóticos confirmados através anátomo-patologia, um dos quais tinha múltiplos aneurismas. Todos quatro pacientes faleceram, sendo que três diretamente relacio. nados à rotura dessas lesões. Nesses estudos os autores concluem que aneurismas micóticos ocorrem mais comumente nas endocardites agudas do que tardiamente nas formas subagudas, e que o tratamento dessas lesões demosntradas pela angiografia, depende da presença ou ausência de hemorragia, localização anatômica, e curso clínico do paciente. A cicatrização com o tratamento antimicrobiano pode ocorrer. Entre 78 pacientes com endocardite bacteriana provada por autópsia duran. te o periodo de 1951 a 1963 , seis pacientes com aneurisma micótico cerebral sucumbiram por rotura dos mesmos num total de 16 , dentro das três primeiras semanas do início dos sintomas da doença básica ${ }^{4}$. Em nosso material, dois casos de aneurisma micótico cerebral foram constatados, em 15 autópsias realizadas.

Desordens convulsivas de caráter focal ocorrem em pacientes com endocardite bacteriana e são usualmente secundárias a fenômenos embólicos ou a abscessos cerebrais. Convulsões generalizadas são mais sugestivas de neurotoxicidade à penicilina ou a distúrbios metabólicos, principalmente em pacientes ido. sos ou que tenham insuficiência renal. Sete pacientes de nossa série tinham lesões de fundo de olho compatíveis com manchas de Roth $e$ que, quando presentes, são de alto valor diagnóstico em confronto com outros achados clínicos ${ }^{17}$. Quatro dos 15 pacientes necropsiados em nosso presente estudo apresentaram hemorragia sub-aracnoidea. Não ficou provado, porém, o fato de tal hemorragia estar rela. cionada com a rotura de aneurisma micótico, como chama atenção Mitchell e Angrist ${ }^{35}$. Outros achados importantes em nosso material, no que concerne a anátomo-patologia, foram a presença de focos de verdadeiras encefalites, infartos e hemorragias cerebrais, que ocorreram em 9 e 8 de 15 autópsias, respectivamente. As lesões de infartos e hemorragias usualmente são secundárias a tromboembolismo cerebral, dano vascular, rotura de aneurismas, vasculite cerebral ou à tendência à hemorragia exibida pelos pacientes com endocardites infecciosas. Processos de endarterites podem ocorrer no curso das endocardites bacterianas. Usualmente são uma resposta dos vasos a toxinas, ação direta dos germes nas paredes dos vasos ou ainda resposta imunológica 
com depósito de complexos imunes na parede vascular com consumo de complemento ${ }^{1}, 44$, 2659 . Aspectos raros são os ependimite, mie-' lite, radiculoneurite e vasculite cerebral difusa.

\section{SUMMARY}

The authors make a revision of 103 cases of infectious endocarditis, 52 of which brought about neurologic manifestations. I? the 52 cases showing neurologic problems, 39 died (75\%), while in the other 51 cases showing no alterations of the nervous system only 18 evolved to death $(35,3 \%)$.

The present series of infectious endocarditis with neurologic manifestations was dominat in the male sex. The more affected age groups were children, adolescents and young adults. Another significant peak was shown by patients more than 50 years old. For the diagnosis of infectious endocarditis in the present study, classical criteria were adopted in addition to a few other ones which were recognized to be extremely useful in the process of accumulating experience, as paralel observation was applied to those changes of etiological patterns and to those alterations of clinical specters of the disease, which resulted from many of the factors here described.

The major neurologic diserders detected were meningeal manifestations, 25/52 $(48,1 \%)$, behavior alterations, $20 / 52(38,4 \%)$ motor phenomena (paralysis and paresis), $20 / 52(38,4 \%)$, alterations of the level of consciousness (torpor or coma), plus a few less commonones, such as cephalea, $16 / 52$ $(30,7 \%)$, alterations of cranial pairs, $14 / 52$ (26,9\%), convulsions, $10 / 52$ (19,2\%), aphasia, $7 / 52(13,5 \%)$.

Multiple neurologic manifestations were frequent in the same patient. These alterations were practically the opening and dominant feature of the clinical scene in many cases of acute endocardites. Most common were: meningeal syndrome, vascular syndrome and toxic encephalopathy. Due to multiple neurologic manifestations in the same patient it was difficult to establish criteria linking the neurologic lesion to the prognostic although in states of profound coma, convulsion, pronounced motor disorders, meningitis and behavior alterations, isola- ted or in association, this prognostic becomes rather more serious.

The germ more often found in our series was the staphylococcus aureus, related to acute forms of endocardiac infection, associated with valve destructive process and serious neurologic alterations, such as meningitis, encephalitis, infarcts, hemorrhages and cerebral abscesses.

$A$ description is given of the major neurolo. gic findings related to the pathology and of the conclusions draw upon reflexion over the material analysed and the experience collected. A review of the existing literature on the disease, from the initial to the lates studies, clearly points out to the importance of the theme to which different authors have made remarkable contributions.

\section{REFERÊNCIAS BIBLIOGRAFFICAS}

1. ALAJOUANINE, T.; CASTALIGNE, P.; LHERMITTE, F.; CAMBIER, J. The cerebral arteritis of bacterial endocarditis: its late complications (Abstract) - JAMA, 170: 1858, 1959.

2. ANTEL, J. J.; ROME, H. P.; GERACl, J. E.; SAYRE, G. P. - Toxic-organic psychosis as a presenting feature in bacterial endocarditis - Proc. Mayo Clin. 30:45, 1955.

3. AUSTRIAN, R. - Pneumococcal endocarditis, meningits and rupture of the aortic valve -- Arch. Inst. Med., 99: $539,1957$.

4. BADEMOSI, C.; FALASE, A. O.; JAIYE. SIMI, F. and BADEMOSI, A. - Neuropsychiatric manifestations of infective endocarditis: a study of 95 patients at Ibadan, Nigeria - J. of Neur., Neuros. and Psychiat., 39:325, 1976.

5. BAWA, Y. S. and WAHI, P. L. - Subacute bacterial endocarditis: meningeal complications - Texas Med., 57:159, 1961.

6. BELL, W. E. and BUTLER C. - Cerebral mycotic anerisms in children Neurology, 18:81, 1968.

7. BERGEN, S. S. and DERMKSIAN, G. Meningeal manifestations of subacute bacterial endocarditis - N. Y. State J. Med., 57:3683, 1957.

8. BRUETSCH, W. L. - The histopathology of the psychoses with subacute bac- 
terial and chronic verrucose rheumatic endocarditis - Am. J. Psychiat., 95:335, 1938.

9. CANTU, R. C.; LE MAY, M. and WILINSON, H. A. - The importance of repeated angiography in the treatment of mycotic-embolic intracranial aneu. risms - J. Neurosurg., 25:189, 1966.

10. CARPENTER, R. R.; PETERSDORF, R. G. - The clinical spectrum of bacterial meningitis - Am. J. Med., 33:262, 1962.

11. CATES, J. E. and CHRISTIE, R. V. Subacute bacterial endocarditie. A review of 442 patients - Q. J. Med., 20:93, 1951.

12. CLAUDE, H. and OURY, P. - Les accidents nerveux de l'endocardite maligne prolongueé - Rev. de Méd., 39: 449, 1922.

13. Clinicopathologic conference: A case of staphilococcal septicaemia with endocarditis and cerebral abscess demonstrated at the Royal Postgraduate Medical School., Brits. Med. J., 479:482, 1967.

14. COOPER, E. S.; COOPER, J. W.; SHNABEL, T. G. - Pitfalls in the diagnosis of bacterial endocarditis - Arch. Ind. Med., 118:55, 1966.

15. DE JONG, R. N. - Central nervous system complications in subacute bacterial endocarditis - J Nerv. e Ment. Dis. 85:397, 1937.

16. DILLON, J. C.; FEINGENBAUM $H_{\text {.; }}$ KONECKE, L. L et al. Echocardiographic manifestations of valvular vegetations - Am. Heart. J., 86:698, 1973.

17. DOHERTY, W. B.; TRUBEK, M. - Significant hemorrhagic retinal lesions in bacterial endocarditis (Roth's spots) - JAMA, 97:308, 1931.

18. DOWLING, H. F.; LEPPER, M.; CALDWELL, E. R. and SPIES, H. W. Staphilococcal endocarditis: an analysis of 25 cases treated with antibiotics - Medicine, 31:155, 1952.

19. FETTERMAN, J. L. and ASHE, W. F. Cerebral debut of certain cases of cardiac disease - OHIO M. J., 34: 1354, 1938.

20. FRIEDBERG, C. K. - Subacute bacterial endocarditis: revision of diagnostic criteria and therapy - JAMA, 144: $527,1950$.
21. FRIEDBERG, C. K.; GOLDMAN, H. M.; FIELD, L. E. - Study of bacterial endocarditis: comparisons in ninetyfive cases - Arch. Inter. Med. (Chicago) - 107:6, 1961.

22. GATES, E. M.; KERNOHAN, J. W.; CRAIC, W. M. - Metastatic brain abscess - Medicine (Balt.), 29:71, 1950.

23. HARRIS, G. A. - Subacute bacterial endocarditis presenting with meningitis - Brit. Med. J., 2:1530, 1965.

24. HARRISON, M. J. G. and HAMPTON, J. R. - Neurological presentation of bacterial endocarditis - Nr. Med. J., 2:148, 1967.

25. JONES, H. R.; SIEKERT, R. G. and GE. RACI, J. E. - Neurologic manifestations of bacterial endocarditis Ann. Int. Med. 71:21, 1969.

26. KAYE, D. - Infective endocarditis University Park Press, 1976.

27. KERNOHAM, J. W.; WOLTMAN, H. W. and BARNES, A. R. - Involvement of the nervous system associated with endocarditis - Arch. Neurol. e Psychiat., 42:789, 1939.

28. KERR, A. Jr. - Subacute bacterial endocarditis - Springfield III, 1955. Charles $C$. Thomas.

29. KRINSKI, C. M. and MERRIT H. H. Neurological manifestations of subacute bacterial endocarditis - New Enql. J. Med., 218:563, 1938.

30. LAHOZ, H.; ASIM, M.; CORRAL, R. DEL; MENES, B. - Complicaciones neurologicas de la endocarditis bacterianas - Rev. Clin. Esp., 122:327, 1971.

31. LERNER, P. I. and WEINSTEIN L. Infective endocarditis in the antibiotic era - N. Engl. J Med., 274: 259, 1966.

32. LIBMAN, E. and FRIEDBERG, C. K. Subacute bacterial endocarditis,, 2.a ed. New York, 1948, Oxford University Press.

33. LUPI, E.; HORWITZ S.; PAREDES, A.; ARROYO, L. S.; CONTRERAS, R. - Transtornos Neurológicos de la endocarditis bacteriana - Arch. Inst. Cardiol. Mex., 43:558, 1973.

34. MEAD, R. H. - Staphylococcal bacteriana and endocarditis - Circulation, 19:440, 1959. 
35. MITCHELL, N. and ANGRIST, A. - Intracranial aneurysms: a report of thirtysix cases - Ann. Int. Med. 19: 909, 1943.

36. Mc DONALD, C. A. and KORB, M - Intracranial aneurysms ... Arch. Neur. e Psychiat., 42:298, 1939.

37. MORGAN, W. L. and BLAND, E. F Bacterial endocarditis in the antibiotic era - Circulation, 19:753, 1959.

38. NEAL, J. B.; JACKSON, H. W. and APPELBAUM, E. - Neurological complications of subacute bacterial endocarditis - New York J. Med., 36:1819, 1936.

39. OSLER, W. - The Gulstonian lectures on malignant endocarditis, Brit. Med. J. $-1: 467,1885$.

40. PANKEY, G. A. - Subacute bacterial endocarditis at the University of Minnesota Hospital, 1939 through 1959 Ann. Inter. Med. - 55:550, 1961.

41. PANKEY, G. A. - Acute bacterial endocarditis at the University of Minnesota Hospital - $1939-1959-$ Am. Heart J., 64:583, 1962.

42. PEARSE, M. L. and GUZE, L. B. - Some factores affecting prognosis in bacterial endocarditis - Am. J. Psychiat., 95:335, 1938.

43. PRICE, E. C.; HEADLEY, R. N. and SAWYER, C. G. - Bacterial endocardits. Its behavior in the elderly $-\mathrm{N}$. C. Med. J., 23:284, 1962.

44. PRUITT, A A.; RUBIN, R. H.; KARCHMER, A. W.; DUNCAN, G. W. Neurologic complications of bacterial endocarditis - Medicine, 57:329, 1978.

45. RABINOWITZ, M. A.; MARCUS, I. H. and WEINSTEIN, J. - Subacute bacterial endocarditis with large brain abscess - JAMA, 98:806, 1932.

46. RABINOVICH, S.; EVANS, J.; SMITH, I. M.; JANUARY, L. E. - A longterm view of bacterial endocarditis: 337 cases, 1924 to 1963 , Ann. Intern. Med. - 63:185, 1965.

47. RAY, H.; WAHAL, K. M - Sub-arachnoid hemorrhage in subacute bacte- rial endocarditis - Neurology (minneap.), 7:265, 1957.

48. ROACH M. R.; DRAKE, C. G. - Ruptured cerebral aneurysms caused by micro-organisms - New Eng. J. Med., 273:240, 1965.

49. SIEKERT, R. G. - Neurological complications of bacterial endocarditis Post grad. Medicine, 149, 1971.

50. SMITH, W. F. - Meningitis secondary to subacute bacterial endocarditis New Eng. J Med., 220:578, 1939.

51. SMITH, R. F.; SZILAGYI, D. E.; COLVILLE, J. M. - Surgical Treatment of Myocotic aneurysms - Arch. Surg. (Chicago), 85.663, 1962.

52. THAYER, W. S. - Studies on bacterial (infective) endocarditis - Johns Hopkins Hosp. Rep., 22:1, 1926.

53. THOMPSON K. R.; MANTO, N. C. and GRANIAK, R. - The reliability of Echo in the diagnosis of infective endocarditis - Radiology, 125:473, 1977.

54. TOMPSETT, R. - Bacterial endocarditis: change in the clinical spectrum Arch. Int. Med., 119:329, 1967.

55. TOOLE, J. F. and PATED, A. N. - Cerebrovascular disorders - New York, 1967. Mc Graw-Hill Book Co.

56. TOONE, E. C. - Cerebral manifestations of bacterial endocarditis - Ann. Int. Med., 14:1551, 1941.

57. TURNBULL, H. M. - Intracranial aneurysms - Brain, 41:50, 1943.

58. VOGLER, W. R.; DORNEY, E. R.; BRIDGES, H. A. - Bacterial endocarditis: a review of 148 cases $-\mathrm{Am}$. J. Med., 32:910, 1962.

59. ZIMENT, I. - Nervous system complications in bacterial endocarditis Am. J. Med., 47:593, 1969.

60. WEINSTEIN, L. and RUBIN, R. H. Infective endocarditis $-1973-$ Prog. Cardiovasc. Dis., 16:239, 1973.

61. WEINSTEIN, L. and SCHLESINGER, J. J. - Pathoanatomic, patho-physiologic and Clinical correlations in endocarditis - N. Engl. J. Med., 291, 832, $1122,1974$. 